\title{
The Influence of Institutional Retention Climates on Student Persistence to Degree Completion: A Multilevel Approach
}

\author{
Leticia Oseguera · Byung Shik Rhee
}

Received: 28 March 2008/Published online: 3 April 2009

(C) The Author(s) 2009. This article is published with open access at Springerlink.com

\begin{abstract}
Using multi-institutional data from the Cooperative Institutional Research Program's (CIRP) annual survey of entering freshmen, the Higher Education Research Institute's (HERI) Faculty Surveys, campus registrars' offices, and IPEDS data, we evaluated the extent to which peer institutional retention climates and faculty perceived campus climates influenced individual 6-year retention rates. We used hierarchical generalized linear models (HGLM) to examine the extent to which institutional climate (as measured by peer institutional retention climate and faculty perceived climate), net of students' ability, expectations, and family socioeconomic status, influence students' persistence behavior. We found that institutional retention climate, as defined by a student body's aggregated report of withdrawal intentions, did independently determine whether a student would persist or not. While past research has overlooked peer and faculty climates, the results from this work call for the attention of peer institutional retention climates.
\end{abstract}

Keywords Degree completion - Faculty climate - Institutional retention ·

Retention · Peer climate

\section{Introduction}

Student retention has attracted steady attention from scholars and practitioners in the higher education community (Astin 1964, 1993; Tinto 1975, 1993; Bean 1980; Cabrera et al. 1993; Braxton 2000). As such, the literature on college student retention is replete with scholarship advancing our knowledge of what contributes to a student's ability

\footnotetext{
L. Oseguera $(\bowtie)$

Department of Education, University of California, Irvine (UCI), 2001 Berkeley Place North \#2054, Irvine, CA 92697-5500, USA

e-mail: oseguera@uci.edu

\section{B. S. Rhee}

Department of Education, College of Sciences in Education, Yonsei University, 262 Seongsanno, Seodaemun-gu, Seoul 120-749, Korea

e-mail: beyoung@yonsei.ac.kr
} 
(or inability) to complete college. Researchers have evaluated retention from a student perspective and shown that high school academic achievement, socioeconomic status, gender, commitment to earning a degree, and social and academic involvement all influence degree completion (Astin 1993; Cabrera and Nora 1996; Tinto 1993). In particular, we know that students who are socially disadvantaged, academically less prepared, and who experience a lack of resources and support from significant others, are less likely to stay in college (Astin 1993; Braxton 2000; Seidman 2005). We also know that those who feel isolated or lack a sense-of-belonging during their early years of college are more likely to leave (Hurtado and Carter 1997; Hausmann et al. 2007). We have a wealth of research available to explain college student retention from an individual, student perspective.

From an institutional perspective, while we have information on institutional context factors and their effect on degree completion, organizational analyses are limited by the fact that they mainly tend to evaluate the influence of structural aspects of an institution (Oseguera 2005-2006; Sjoberg 1999; Titus 2004, 2006a) and until recently, the organizational culture of an institution (Berger 2000, 2001-2002; Braxton 2000; Kuh 2001-2002). For example, size, control, selectivity, expenditures, and financial aid awards have been shown to contribute to a student's ability to finish college (Astin 1993; Berger 2000, 2001-2002; Berger and Milem 2000; Oseguera 2005-2006; Titus 2004, 2006a, b). We also know that individual peer and faculty contact and interactions influence persistence behavior but know less about these groups' collective influence on persistence decisions. What is lacking then in institutional analyses of degree completion is an attendant emphasis on peer and faculty climates. In other words, what effects do peer and faculty attitudes and behaviors in the aggregate (i.e. institutional climates) have on student degree completion?

For our analysis, we used hierarchical generalized linear models (HGLM) to examine the extent to which institutional climate (as measured by peer intentions to persist and faculty perspectives of student learning environments), net of students' ability, expectations, and family socioeconomic status, influence students' persistence behavior. Multilevel modeling will allow us to separate differences in student retention behavior related to individual (Level-1) characteristics (i.e. SES) from those related to school context factors (Level-2).

This research differs from other retention studies as it is multi-institutional and examines institutions of differing selectivity. Finally, this study builds upon previous studies on the role of peer norms in student persistence (Berger and Milem 2000; Bonous-Hammarth 2000; Titus 2004), and extends prior research by examining peer institutional retention climates and faculty-perceived student climates. Given the complexity of institutional context, under which institutional climate is subsumed, and its potential to influence degree completion, research that further uncovers the factors explaining the differences in student persistence between colleges and universities will benefit both educators and students.

\section{Background and Literature Review}

In a comprehensive review of student retention studies of the last three decades, Pascarella and Terenzini (2005) point out that the structural characteristics of higher education institutions, such as institutional quality, control, type, and gender and racial compositions, are minimally and indirectly associated with a student's decision to persist. Although their conclusion appears reasonable, it is limited in that the studies they reviewed primarily focused on structural dimensions of the institution. Recent studies have shown that more diverse dimensions of institutional context, such as campus racial climates, peer cultures, 
and faculty normative environments are involved in students' departure decisions (Berger 2000, 2001-2002; Titus 2006a, b).

For this study we primarily evaluate faculty perspectives of the climate for students and peer normative contexts which we collectively term institutional climate. Climate, according to Holland (1997), can be inferred from the kind of people that make-up a group. Both the general character and dominant features of an environment, "reflect the typical characteristics of its members" (Holland 1997, p. 42). For this study, we incorporate the perspectives of faculty and students to describe the climate for student retention. Norms, on the other hand, are defined as "prescriptive or proscriptive expectations or standards of behavior, and those who exert normative influence do so by telling others how they should or should not behave" (Bank et al. 1990, p. 210). According to Weidman (1989), it is the faculty who create the respective norms and values of academic environments. Faculty norms help determine an institutional climate to which students are subsequently exposed. While our measures do not explicitly measure faculty norms according to Bank et al.'s (1990) definition, they nevertheless help to describe the learning environments for students on campus and do provide us with a general sense of the standards of behavior for student learning. As such, we employ aggregate faculty perspectives on the learning environment for students as one component of an institution's climate. These faculty perceived climates are important to consider as they represent powerful avenues for the socialization of students.

Faculty behaviors and attitudes have been analyzed rather extensively with respect to their effect on undergraduate education (Astin 1993; Braxton et al. 1996; Pascarella and Terenzini 2005). Some researchers have found that faculty norms and self-reported faculty interactions with students influence student behavior above individual, student characteristics (Comeaux 2005a, b). In a single institution study of undergraduates at a large Midwestern university, Bank et al. (1990) found that faculty norms significantly affected students' positive university intentions which then affected the student's decision to either remain enrolled or drop out of college. One limitation of this study is that the faculty norms were created by asking students to attribute particular norms to the faculty at their institution, not by asking the faculty themselves.

In a multi-institutional study of undergraduates, Astin (1993) found that aggregated faculty measures including faculty reported humanistic orientation, faculty morale, and faculty diversity orientation all had significant positive effects on student persistence behavior (Astin 1993). However, other studies of faculty norms ${ }^{1}$ and behavior find little to no influence of faculty on student outcomes as researchers suggest that the effects of faculty are mediated by the effect of student interactions (Milem 1998). With the exception of a few notable studies, relatively little is known about the aggregate effects of faculty perceptions of institutional climate on student retention. Accordingly, this work offers a deeper understanding of faculty perspectives and persistence behavior.

In evaluating student behavior, though, we also cannot dismiss peer normative influences on student behavior and hence include peer normative contexts in our definition of institutional climate. Bank et al. (1990) and Steele (1997) show that the contextual effects of peers i.e. expectations and standards, are even stronger influences on student behavior

\footnotetext{
1 The term "norm" has been utilized in the literature to describe a variety of contexts and often times does not adhere to the Bank et al. (1990) definition we employ in this manuscript. In some of the studies reviewed in this section (e.g., Astin 1993; Milem 1998), faculty "norms" could more aptly be termed faculty perceptions or faculty attitudes. Since it is not in the purview of this manuscript to debate what pure "norms" are, we do include a variety of literature that evaluates faculty perspectives but do so with the recognition that researchers define these measures differently. We refrain from using the word "norm" unless it adheres to the Bank et al. definition or it is the word employed by the researcher we are evaluating.
} 
than is modeling behavior (or the pressure to copy behavior). Although the study of peers have been extensively studied in the literature as potentially influencing educational outcomes (Astin 1993; Oseguera 2005-2006; Tierney and Colyar 2005; Weidman 1989), with a few notable exceptions, few attempts have been made to explicitly study the effects that peer climates in the aggregate may have on degree completion (Astin 1993; Berger and Milem 2000). A good amount of scholarly effort is devoted to understanding the role of student peer characteristics in student development, but not in student persistence (Feldman and Newcomb 1969; Weidman 1989). Moreover, the available literature on peer normative effects is limited by the fact that most empirical studies are single institution studies and most rely on data from highly selective campuses.

Much of the difficulty in examining peer normative contexts is the ability to contend with selection bias. That is, being able to separate if the so-called effect of peers is truly the effect of peers or if it is simply peers choosing their friends and emulating behavior of already like-minded people. In recent years scholars have attempted to examine individual peer effects on college student academic achievement (Sacerdote 2001; Zimmerman 2003; Winston and Zimmerman 2004), which in turn, influences college student completion (Astin 1993; Oseguera 2005-2006). In a study of college freshmen attending Williams College, Zimmerman (2003) found that students with average standardized test scores were most influenced by having a roommate with a low SAT score which resulted in their achievement in college going down and conversely, being exposed to a roommate with high SAT scores corresponded with academic achievement raising for the student with the initial average SAT score. This finding was confirmed in a single-institution study of Dartmouth freshmen (Sacerdote 2001) and a later study of 5,400 students attending three highly selective colleges (Winston and Zimmerman 2004). However, other studies examining peer effects showed little to no peer effects on academic performance as measured by changes in grade averages. In a study evaluating students' background characteristics on the academic credentials of their college roommates using data from four classes of students at Wellesley College, where roommate assignment was relatively random, McEwan and Soderberg (2006) concluded there were no direct peer effects of combined SAT verbal and math scores on students' grade point averages, although there was some evidence that students' individual SAT math scores had small nonlinear effect on their roommates' achievement. They suggested that roommate peer effects were not a key determinant of students' average academic outcomes at Wellesley College.

Among the studies examining institutional effects on student retention, Titus (2004), using Beginning Postsecondary Students (BPS) 96/98 Longitudinal Study and Integrated Postsecondary Education Data Systems (IPEDS) 95/96 data, showed that peer characteristics, institutional structure, and aggregated experiences of students were significantly associated with student persistence. Porter and Swing (2006) reviewed the effects of various aspects of first-year seminars including study skills and academic engagement, college policies, campus engagement, peer connections, and health education on student persistence, and found institutional environments that improved study skills and integrated health education to be significant. Bonous-Hammarth (2000) also showed that the organizational climate measured by student engagement and disengagement was significantly related to student departure behavior. Berger and Braxton (1998) also examine the role of organizational attributes in the persistence process. Using path analytic methods on 1,343 freshmen in a highly selective private residential research I university, the authors showed that in addition to individual background characteristics, initial institutional commitment, social integration, subsequent institutional commitment, and organizational attributes (e.g., a student's opinion regarding institutional communication, fairness in policy and rule 
enforcement, and the ability to participate in decision making) influence not only social integration, but also intent to reenroll. Evaluating 45,000 seniors at 305 institutions in spring of 2001 using the National Survey of Student Engagement, Pike and Kuh (2006) examined the relationship among structural diversity, informal peer interactions and perceptions of the campus environment and concluded that institutional characteristics and initiatives can have direct and powerful effects on student behavior (Pike and Kuh 2006).

In addition to individual peer effects (i.e. one-on-one contact and interactions between peers), researchers also advocate for a better understanding of peer normative context effects (i.e. aggregated peer attitudes, behaviors, and expectations for standards of behavior). Examining the effects of peers under the larger heading of institutional context, Dey (1996), using a peer normative framework on students who were freshmen in 1985 and seniors in 1989 showed how the peer context influenced students' political beliefs during college. Dey (1996) documented how conservative students attending schools with peer conservative cultures became more conservative over time while left-leaning students became more left-leaning over time when exposed to a peer culture of left-leaning students. In a single institution study, Thomas (2000) suggests that peers directly influence individual persistence via social integration. Using multiple institutions of differing selectivity, Oseguera (2005-2006) found peer contexts such as peer intellectual selfesteem, peer SES, and peer scientific orientation to influence degree completion above individual level characteristics. In short, there is a small but growing body of evidence that demonstrates peer normative effects in educational outcomes including degree completion.

\section{Conceptual Framework and Research Questions}

The conceptual framework guiding this study is adapted from Titus (2004). Titus (2004) developed a comprehensive conceptual model to examine student persistence. Titus' contribution is his attention to institutional context factors including peer climates. Titus' work incorporates Bean's (1990) work on individual, student level characteristics, and environmental pull variables with work by Berger and Milem (2000) that evaluates institutional level characteristics' influence on degree completion. Before elaborating on the conceptual frame for this work, it is important to acknowledge the work of Tinto (1993). While Tinto's theoretical framework is central in the study of individual student departure in that explicit attention is paid to student characteristics and within college experiences, our work differs in that we are primarily highlighting the role of institution level variables in understanding departure. Bean's theoretical framing is more pure in its attention to structural features of a college campus. Since our attention is better understanding explicitly the structural and organizational features, we feel that a modified version of Bean's model and subsequently Titus' model is more appropriate. In particular, utilizing resource-dependency theory and incorporating BPS 96/98 and IPEDS 95/96, Titus (2004, 2006a, b) examined institutional revenue and expenditure pattern on students' persistence and found that student characteristics, college experiences, external pull (work for pay, financial need), institutional control variables (structural: private, HBCU, size; selectivity), revenue patterns (state, tuition, grants), and expenditure patterns (instruction, research, etc.) influenced degree completion among low-income students. Titus' contribution is to show the independent effects of institutional level characteristics and, in particular, various peer climates on degree completion. Therefore, this study also incorporates institutional context factors.

Based on extensive reviews of the literature as well as organizational scholars' suggestions of integrating multiple theories, we augment Titus' (2004) frame by incorporating 
additional conceptual frames from organizational theory, in particular, institutional climate. The institutional climate includes those characteristics of a campus' members that illustrate its character. Here we borrow from Hurtado et al's. (1999) work on campus climates as well as Bonous-Hammarth's (2000) definitions of organizational climates. Bonous-Hammarth (2000) examines value congruence and organizational climates for undergraduate persistence. She defines organizational climates as aggregates of student engagement (or disengagement) on campus and found that value congruence between students' espoused values and institutional norms minimized students' decision to leave an institution. Among the borrowed concepts from Hurtado et al. (1999) are their notions of climate having both a structural and a psychological dimension. Campus climate is defined by normative perceptions and attitudes, and ambiance of the environment. We suggest that these normative experiences originate from both student and faculty attitudes and experiences. While Titus (2004) explores peer climate from a student's perspective, one potential shortcoming is his inattention to faculty perceptions of students' environments. We augment this conceptual frame to include faculty perceived learning environments for students as faculty behavior and beliefs also help to define an institution's climate and have been shown to impact students' decisions in college (Astin 1993; Braxton 2000; Seidman 2005; Tierney 1990). In fact, according to Weidman (1989), it is the faculty who create the respective norms and values of academic environments. Consequently, evaluated in this conceptual frame are aggregated faculty opinions about the climate for students such as how much the campus values diversity and the emphasis placed on teaching over research.

Collectively, the conceptual frame guiding this study posits that at the student level, student background characteristics, experiences, and attitudes exert an influence on students' probability of remaining enrolled in college. Simultaneously, the institutional level characteristics also exert an influence on student behavior. That is, aggregated peer experiences also influence one's chances of completing a degree beyond one's personal experiences. In addition to the peer climates introduced by Titus (2004), we include peer retention climates as potential influences of degree completion. Finally, how faculty perceive the climate for students is also suggested to influence probabilities of degree completion. Thus, faculty perceived learning environments for students may also contribute to better understanding students' persistence behaviors. In other words, the extent to which a student body (or faculty) collectively espouse a certain characteristic, that aggregated characteristic is also manifested throughout the campus and can in turn influence student behavior. For this study, it is hypothesized that the average expectations to complete college at a particular campus and faculty perceptions of learning environments for students (or what we term, institutional climate) may also exert an influence on average institutional probability of persistence (see Fig. 1).

This combined theoretical frame is posited to influence student retention and is particularly useful because particular emphasis is placed on the unique effects of peer and faculty perceived institutional contexts (or institutional climate). This study addresses two research questions:

1. Does peer retention climate influence the likelihood of persistence to degree completion, taking into account student and institutional structural characteristics, and faculty-perceived campus environment?

2. Does the faculty-perceived campus environment influence the likelihood of undergraduate persistence to degree completion, taking into account student characteristics and institutional structural characteristics? 


\section{Student Level}

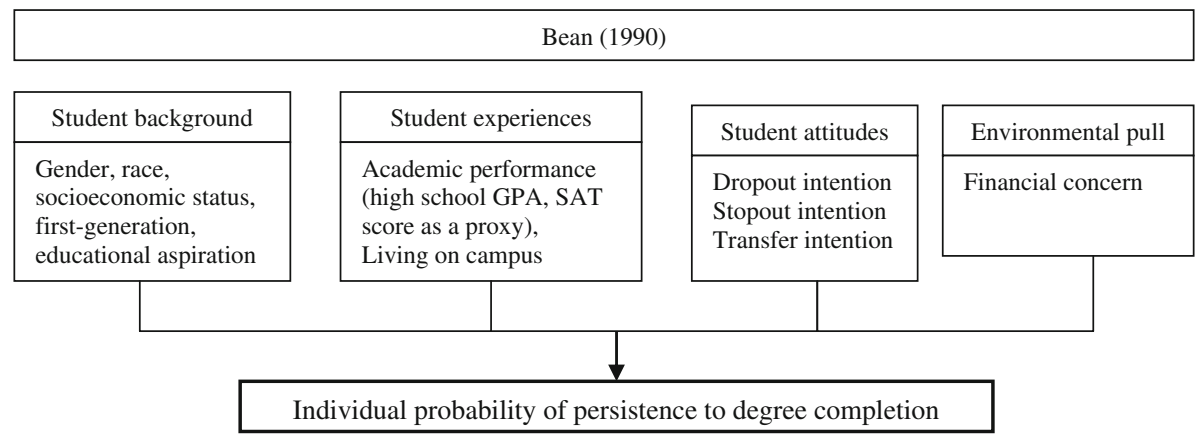

\section{Institutional Level}

\begin{tabular}{|c|c|}
\hline Berger-Milem (2000) & $\begin{array}{c}\text { Hurtado et al. (1999), Bonous-Hammarth (2000), } \\
\text { Weidman (1989) }\end{array}$ \\
\hline
\end{tabular}

Student peer characteristics: high school GPA, financial concern, degree aspiration, socioeconomic status, gender, first-generation

\section{Structural demographic}

characteristics: private, four-year, institutional size, selectivity, racial diversity

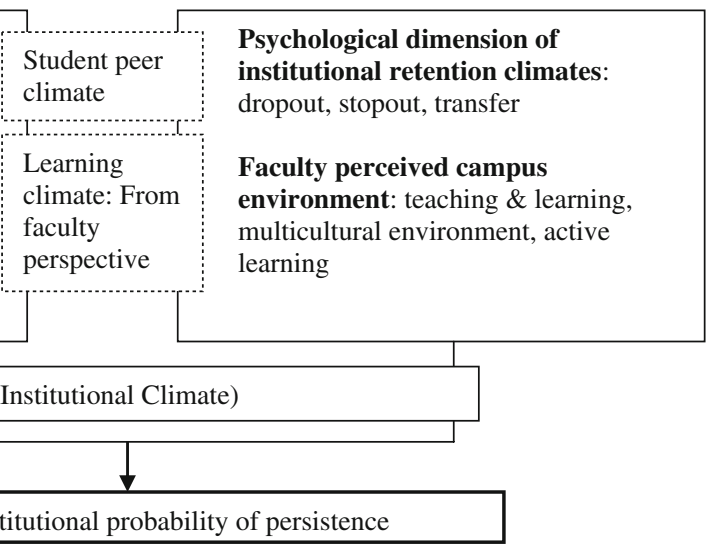

Average institutional probability of persistence

Fig. 1 Modified conceptual model of Titus' (2004) framework of college student persistence

\section{Data, Measures, and Analytic Method}

\section{Data Source and Sample}

Data used for this study were drawn from multiple sources. Student-level data were obtained from a national sample of 262 baccalaureate-granting institutions that participated in the Cooperative Institutional Research Program's (CIRP) annual survey of entering freshmen in the fall of 1994. Six-year degree attainment data were obtained in the summer of 2000 by sending to the registrar at each institution representative rosters containing names of an average of 200 randomly selected entering freshmen who had completed the 1994 survey. ${ }^{2}$ Completion data were provided on close to $100 \%$ of the cases requested. Non-response was attributed to the campus and not the student, minimizing self-selection bias. Faculty

\footnotetext{
${ }^{2}$ For a complete description of the methods used to collect these data, see the American Freshman: National Norms for 1994 and Degree Attainment Rates at American Colleges and Universities.
} 
perceived climate variables were derived from the Higher Education Research Institute (HERI) Faculty Survey's, administered in 1995, 1998, and 2001. To make the institutional measures consistent with the student measures, faculty members surveyed in 1998 or 2001 were selected if they were appointed at the current institutions before 1996. The faculty sample included responses from faculty at 245 institutions. The initial student sample (degree attainment data) started with 56,476 students within 262 four-year colleges and universities.

Some researchers have highlighted the environmental differences between commuter and residential institutions (Astin 1993; Braxton and Hirschy 2005; Cabrera et al. 2005). That is, they show that the peer and faculty climates are distinct. Others have even produced separate models of retention for these institutional types (Braxton et al. 2004). Since analyzing these groups using the same lens is inappropriate, we decided to exclude campuses that were primarily non-residential. ${ }^{3}$ After merging degree attainment data with IPEDS and HERI faculty data, the final sample included 37,006 students attending 170 four-year colleges and universities in the U.S. The average sample size within institutions was 219 , ranging from 25 to 400 . More than half of the undergraduate sample was female $(58 \%)$. Thirteen percent of the sample was students of color. Two-thirds of the students received an average high school grade of a "B+" or higher and roughly $80 \%$ of the students' highest educational goals were to obtain at least a Master's degree at any institution. Although these appear to be high educational aspirations, they are only slightly higher than the figures produced in The American Freshman: National Norms for Fall 1994, which documented that $73 \%$ of entering freshmen aspired to a Master's degree or higher (Astin et al. 1994). Further, the average standardized test scores (SAT =1,069) are close to the national average and do approximate a normal distribution. Among the faculty sample, $98 \%$ worked as full-time faculty members. Thirty-three percent were female and $8 \%$ identified themselves as faculty of color. Sixty-three percent of the sample was tenured and $37 \%$ were untenured. These sample characteristics closely approximate the figures produced in The American College Teacher: National Norms for 2001-2002 HERI Faculty Survey (see Lindholm et al. 2002). In terms of institutional characteristics, this sample over-represents private institutions (83\%) and four-year liberal arts and state colleges (84\%) as opposed to Masters Comprehensive or Research Universities.

\section{Measures}

The dependent variable, persistence to degree completion, is defined as having completed an undergraduate degree within 6 years or being enrolled in the same institution over this 6-year time period. We consider students who were still enrolled six plus years as degree completers. Roughly $67 \%$ of students in this sample satisfied this definition. Degree completers are scored as 1 and non-completers are scored as 0 . The independent studentlevel (Level-1) variables were guided primarily by Titus' (2004) reformulated conceptual framework and include student background characteristics, high school achievement, educational aspirations, and a student's reported intention to leave the institution prior to obtaining a degree (see Table 1). Student background characteristic measures include gender, racial/ethnic group identification, first-generation status, socioeconomic status, and reported financial concern. The racial groups included in the analyses include White, African American/Black, Latina/o, Asian American/Asian, and "Other" racial group with

\footnotetext{
3 The Carnegie classification suggests that institutions with fewer than $25 \%$ of degree-seeking undergraduates living on campus or fewer than $50 \%$ enrolled full-time are classified as primarily nonresidential. Among our sample, 4 campuses satisfied this definition and were thus excluded.
} 
Table 1 Descriptive statistics of sample ( $n=37,006$ at Level-1; $n=170$ at Level-2)
Note 1: missing values were imputed with EM algorithm

Note 2: high school GPA $(1=\mathrm{D}$, $2=\mathrm{C}, 3=\mathrm{C}+, 4=\mathrm{B}-$, $5=\mathrm{B}, 6=\mathrm{B}+, 7=\mathrm{A}-$, $8=\mathrm{A}$ or $\mathrm{A}+$ ); educational degree aspiration $(1=$ less than Bachelor's degree,

2 = Bachelor's degree

3 = Master's degree,

4 = Doctorate); dropout, stopout, transfer intentions $(1=$ no chance, 2 = very little chance, $3=$ some chance, $4=$ very good chance)

\begin{tabular}{lrccc}
\hline Variable & Mean & SD & Min & Max \\
\hline Dependent variable & & & & \\
Graduation within 6 years & 0.67 & 0.47 & 0 & 1 \\
Level-1 independent variables & & & & \\
Gender: female & 0.58 & 0.49 & 0 & 1 \\
Race: African American/Black & 0.03 & 0.18 & 0 & 1 \\
Race: Latina/o & 0.03 & 0.16 & 0 & 1 \\
Race: Asian & 0.04 & 0.20 & 0 & 1 \\
Race: other race & 0.03 & 0.18 & 0 & 1 \\
First generation college student & 0.14 & 0.35 & 0 & 1 \\
Socioeconomic status & 0.02 & 1.70 & -5.21 & 3.26 \\
Financial concern & 1.90 & 0.66 & 1 & 3 \\
High school GPA & 6.15 & 1.52 & 1 & 8 \\
SAT composite score & 10.69 & 1.72 & 4.2 & 16.0 \\
Educational degree aspiration & 3.17 & 0.72 & 1 & 4 \\
Living in dormitory & 0.90 & 0.30 & 0 & 1 \\
Dropout intention & 1.24 & 0.51 & 1 & 4 \\
Stopout intention & 1.46 & 0.62 & 1 & 4 \\
Transfer intention & 2.07 & 0.86 & 1 & 4 \\
Level-2 independent variables & & & &
\end{tabular}

Level-2 independent variables

Institutional characteristics (aggregated)

$\begin{array}{lllll}\text { High school GPA } & 6.09 & 0.69 & 4.18 & 7.63 \\ \text { Financial concern } & 1.92 & 0.17 & 1.09 & 2.25 \\ \text { Degree aspiration } & 3.13 & 0.30 & 2.43 & 3.72 \\ \text { Percent: first-generation } & 0.15 & 0.09 & 0.02 & 0.43 \\ \text { Percent: living on campus } & 0.90 & 0.13 & 0.28 & 1 \\ \text { Percent: female } & 0.59 & 0.16 & 0.18 & 1 \\ \text { ructural-demographic } & & & & \\ \text { Private } & 0.83 & 0.38 & 0 & 1 \\ \text { Four-year colleges } & 0.84 & 0.37 & 0 & 1 \\ \text { Institutional size } & 2.93 & 3.52 & 0.40 & 21.11 \\ \text { Institutional selectivity } & 9.99 & 1.34 & 7.56 & 13.3 \\ \text { Racial diversity } & 8.21 & 5.87 & 0 & 40\end{array}$

Faculty perceived campus climate environment

$\begin{array}{lllll}\text { Institutional priority on teaching and } & 0.26 & 0.38 & -0.69 & 1.03\end{array}$ learning

$\begin{array}{lllll}\text { Institutional priority on multicultural } & 0 & 0.43 & -1.26 & 1.18\end{array}$ environment

Active learning

$\begin{array}{llll}0.08 & 0.28 & -0.61 & 1.19\end{array}$

Peer institutional retention climate

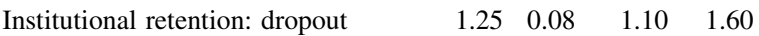

$\begin{array}{llllll}\text { Institutional retention: stopout } & & 1.46 & 0.12 & 1.17 & 2.03\end{array}$

$\begin{array}{llllll}\text { Institutional retention: transfer } & & 2.10 & 0.21 & 1.39 & 2.76\end{array}$ 
White designated as the reference group. First-generation students are defined as those students who report that neither parent has attended college. A student's socioeconomic status is measured by the sum of standardized parental educational attainment $(1=$ less than high school to $4=$ earned a graduate degree) and standardized parental income ( $1=\$ 6,000$ or lower income to $14=\$ 200,000$ or more income). For the financial concern measure, students indicated how much concern they had about their ability to finance their college education ( $1=$ none, $2=$ some, $3=$ major $)$. High school achievement is measured by students' self-reported high school GPA $(1=\mathrm{D}$ to $8=\mathrm{A}$ or A+) and SAT composite score (420-1600). A student's educational aspiration is measured by the selfreported highest degree they intend to obtain, which was collapsed into four categories to be able to be used as an ordinal variable in the analyses $(1=$ less than Bachelor's degree, 2 = Bachelor's degree $3=$ Master's degree, $4=$ Doctorate). Students' intentions to dropout permanently, dropout temporarily (stopout), or transfer to another college before graduating are measured by a student's best guess on those activities at the time of entering college. They were asked to select one of the four choices $(1=$ no chance, $2=$ very little chance, $3=$ some chance, $4=$ very good chance). We use a student's living plan for fall 1994 as a proxy for potential engagement in college. We separated college residence hall from other types of living arrangements since past research has demonstrated the positive effects of dorm life on a number of educational outcomes (Astin 1993; Pascarella and Terenzini 1991, 2005; Seidman 2005). The living plan is dummy-coded as 1 indicating living in college dormitory and 0 for any other type of first-year living arrangement (e.g., living with parents, in private home, fraternity/sorority).

The independent institution-level (Level-2) variable selection is also guided primarily by Titus' (2004) reformulated conceptual frame but also includes constructs adapted from Hurtado et al. (1999) and Bonous-Hammarth (2000). These include aggregated measures of student characteristics and institutional structural characteristics. Titus' (2004) frame is also augmented to include additional peer climates, including institutional retention climates as well as faculty perceptions of the climate for undergraduates. Aggregated studentlevel measures were used at the institution-level to take into account the student composition of institutions. ${ }^{4}$ Institutional structural characteristics include institutional type ( 1 = four-year college, $0=$ university $)$, institutional control $(1=$ private, $0=$ public $)$, and size (full-time equivalent divided by $1,000^{5}$ ). Institutional selectivity is measured by the average institutional SAT composite scores drawn from the College Board database. For estimation purposes, SAT scores were divided by 100 . Racial diversity is measured by the sum of the percentages of minority groups that include African American, Latina/o, and American Indian (Chang 1999). We exclude Asian American students from the formula because some researchers show they exhibit similar characteristics to White students on such measures as parental education levels, socioeconomic status, and baccalaureate degree attainment relative to other minority groups (Conchas 2006; Oseguera 2005-2006). Further, many national research organizations do not consider Asian Americans to be an underrepresented minority (see for example NIH guidelines for determining which groups satisfy underrepresented minority status).

\footnotetext{
${ }^{4}$ We dropped the aggregated measure of socioeconomic status from the model because its variance inflation factor exceeded the tolerable level (VIF = 10). See Appendix Table 5. It is commonly accepted that VIF of 10 or more is indicative of serious multicollinearity involving the corresponding variable (Cohen et al. 2003, p. 423).

${ }^{5}$ Since HLM analysis routinely relies on maximum likelihood estimation, it is recommended to keep the scale of the measures varying by a small margin if possible. We apply this principle for institutional size and standardized test scores.
} 
Faculty-perceived ${ }^{6}$ campus climate was measured by three factors that are hypothesized to influence degree completion. They are institutional priority on teaching and learning, multicultural environment, and active learning. These factors were selected because they are frequently utilized in the literature to examine educational outcomes (Hurtado et al. 1999; Braxton et al. 2000; Pascarella and Terenzini 1991, 2005; Seidman 2005). Further Kuh (2001-2002) states that, "key to developing a success oriented institutional culture is to...focus on the classroom as the primary locus of culture building" (Kuh 2001-2002, p. 37). Institutional priority on teaching and learning was measured by four items, faculty perceptions of institutional emphasis on promoting the intellectual development of students, helping students examine and understand their personal values, developing leadership ability among students, and helping students bring about a change in American society using a scale of $1=$ low priority to $4=$ highest priority. Multicultural environment comprises another aspect of the campus climate for students. It is derived from two items of faculty perceptions of institutional emphasis on recruiting more minority students and creating a diverse multicultural campus environment and is measured on a scale of $1=$ low priority to $4=$ highest priority. Students who report more hospitable campus climates for diversity show gains in educational outcomes such as smoother transitions to college and greater growth in critical thinking and awareness (Hurtado and Carter 1997; Hurtado and Ponjuan 2005; Locks et al. 2008). The use of active learning in undergraduate institutions has also been shown to aid in the student persistence process (Braxton et al. 2000). For this study, active learning consists of four items: the frequency with which faculty report using class discussions, cooperative learning, experiential learning, and group projects. Using the following scale: all, most, some, or none, faculty respondents were asked to indicate in how many of their undergraduate courses they utilized each of these instructional tools. The reliabilities of these factors ranged from .71 to .84 (see Appendix Table 6).

Institutional retention climate was captured by the aggregated measures of students' intention to dropout permanently, dropout temporarily, or transfer to another college before graduating (all measured on a scale from $1=$ no chance to $4=$ very good chance). These measures intend to capture the psychological dimension of the campus climate as Hurtado et al. (1999) suggested. ${ }^{7}$

\section{Analysis}

We used Hierarchical Generalized Linear Models (HGLM) for a dichotomous outcome variable for the analyses. HGLM is an appropriate statistical technique because of its superior estimating ability relative to single-level techniques. With the notable exceptions of Titus (2004, 2006a, b), few studies incorporate HGLM in the design of persistence studies of college students. Multi-level modeling is well suited for this analysis as it accounts for the natural clustering of students within schools. That is, multi-level modeling allows us to

\footnotetext{
${ }^{6}$ Faculty measures were adapted from 3 years of The American College Teacher: National Norms data. Analyses were run to ensure that the faculty make-up in any given year was not significantly different as to alter the meaning of the constructs that were created.

7 Hurtado et al. (1999)'s work suggests that the campus climate may comprise multiple dimensions, such as structural, psychological, behavioral, and historical dimensions, and they must be attended to in order to improve the educational experience of college students. To measure the structural dimension of institutional retention climates, we initially included 1994 cohort graduation rates available in IPEDS 2000, but dropped the measure in the final analysis because of its similarity to the randomly varying intercept, i.e. institutional persistence rate.
} 
separate differences in student retention behavior related to individual (Level-1) characteristics (i.e. high school GPA) from those related to school context factors (Level-2).

To examine whether sufficient variation in degree completion rates existed between institutions, we estimated a fully unconditional model that had no predictors at either Level-1 or Level-2 models. If the degree completion rates significantly vary among institutions, the use of HGLM is warranted. To determine the degree to which variation lies between institutions, following the example of previous studies (Rumberger and Thomas 2000; Titus 2004), we inspected a $95 \%$ confidence interval of average institutional persistence rates using empirical Bayesian estimates. The confidence interval graph showed average institutional persistence rates significantly varied among institutions, and that $95 \%$ of the colleges and universities lay between $33 \%$ and $90 \%$ with respect to the probability of persistence to degree completion; this variation was statistically significant $\left(\tau=.589\right.$, $\mathrm{df}=161, \chi^{2}=3,728.58$, $p<.01) .{ }^{8}$ With these visual and statistical results, we moved on to build up student-level and institution-level models. To address the research questions, we specified the within-college (Level-1) and between-college (Level-2) models to be estimated as follows.

\section{Level-1:}

$$
\begin{aligned}
\log \left[\mathrm{p}_{\mathrm{ij}} / 1-\mathrm{p}_{\mathrm{ij}}\right]= & \beta_{0 \mathrm{j}}+\beta_{1 \mathrm{j}} *(\text { Female })_{\mathrm{ij}}+\beta_{2 \mathrm{j}} *(\text { Black })_{\mathrm{ij}}+\beta_{3 \mathrm{j}} *(\text { Latino/Puerto Rican })_{\mathrm{ij}} \\
& +\beta_{4 \mathrm{j}} *(\text { American Indian })_{\mathrm{ij}}+\beta_{5 \mathrm{j}} *(\text { Asian })_{\mathrm{ij}}+\beta_{6 \mathrm{j}} *(\text { Other Race })_{\mathrm{ij}} \\
& +\beta_{7 \mathrm{j}} *(\mathrm{SES})_{\mathrm{ij}}+\beta_{8 \mathrm{j}} *(\text { Financial Concern })_{\mathrm{ij}}+\beta_{9 \mathrm{j}} *(\text { First Generation })_{\mathrm{ij}} \\
& +\beta_{10 \mathrm{j}} *(\text { Degree Aspiration })_{\mathrm{ij}}+\beta_{11 \mathrm{j}} *(\text { HS GPA })_{\mathrm{ij}}+\beta_{12 \mathrm{j}} *(\mathrm{SAT})_{\mathrm{ij}} \\
& +\beta_{13 \mathrm{j}} *(\text { Living on Campus })_{\mathrm{ij}}+\beta_{14 \mathrm{j}} *(\text { Stopout Intention })_{\mathrm{ij}} \\
& \left.+\beta_{15 \mathrm{j}} * \text { (Dropout Intention }\right)_{\mathrm{ij}}+\beta_{16 \mathrm{j}} *(\text { Transfer Intention })_{\mathrm{ij}}
\end{aligned}
$$

where $\mathrm{p}_{\mathrm{ij}}$ is the probability of completing a program within 6 years.

Level-2:

$$
\begin{aligned}
\beta_{0 \mathrm{j}}= & \gamma_{00}+\gamma_{01} *(\text { AVG }: \text { HS GPA })_{\mathrm{ij}}+\gamma_{02} *(\text { AVG }: \text { Financial Concern })_{\mathrm{ij}} \\
& +\gamma_{03} *(\text { AVG : Degree Aspiration })_{\mathrm{ij}}+\gamma_{04} *(\% \text { First }- \text { Generation })_{\mathrm{ij}} \\
& +\gamma_{05} *(\% \text { Living on Campus })_{\mathrm{ij}}+\gamma_{06} *(\% \text { Female })_{\mathrm{ij}}+\gamma_{07} *(\text { Racial Diversity })_{\mathrm{ij}} \\
& +\gamma_{08} *(\text { Selectivity })_{\mathrm{ij}}+\gamma_{09} *(\text { Size })_{\mathrm{ij}}+\gamma_{10} *(\text { Private })_{\mathrm{ij}}+\gamma_{11} *(\text { Four-yearCollege })_{\mathrm{ij}} \\
& +\gamma_{12} *(\text { Priority on Teaching \& Learning })_{\mathrm{ij}} \\
& +\gamma_{13} *(\text { Priority on Multicultural Environment })_{\mathrm{ij}}+\gamma_{14} *(\text { Active Learning })_{\mathrm{ij}} \\
& +\gamma_{15} *(\text { AVG : Stopout Intention })_{\mathrm{ij}}+\gamma_{16} *(\text { AVG }: \text { Dropout Intention })_{\mathrm{ij}} \\
& +\gamma_{17} *(\text { AVG : Transfer Intention })_{\mathrm{ij}}+\mu_{0 \mathrm{j}} \quad \mu_{0 \mathrm{j}} \sim \mathrm{N}\left(0, \tau_{00}\right) \\
& \beta_{\mathrm{kj}}=\gamma_{\mathrm{k} 0} \quad \mathrm{k}=1,2, \ldots, 16
\end{aligned}
$$

where $\beta_{0 \mathrm{j}}$ indicates average graduation rates for college $j$.

Because the focus of this study is to examine the effect of the institutional context on degree completion, all Level-1 variables were group-mean centered. Group mean centering

\footnotetext{
8 The intraclass correlation is less informative in the case of the logit link function in our study because the level-1 variance is heteroscedastic (Raudenbush and Bryk 2002, p. 298). Nonetheless, when the level-1 random effect is assumed to have a standard logistic distribution with a mean of 0 and variance $\pi^{2} / 3$, the intraclass correlation turns out to be 0.152 , which indicates that about $15 \%$ of variance in graduation rates lies between colleges and universities.
} 
allows us to interpret the Level-1 intercept term, $\beta_{0 \mathrm{j}}$, as the unadjusted mean rate of degree completion for students with average values for personal background, academic achievement, and retention intention variables within an institution. Group-mean centering is useful to disentangle between personal and contextual effects (Raudenbush and Bryk 2002). We allowed only the intercept to vary and fixed all student-level coefficients on the Level-2 model because the focus of our study is on the mean chance of a student's degree completion rather than varying relationships between the student-level variables and the outcome variable, i.e. persistence to degree completion. We also performed a multivariate hypothesis test of the difference between the institution-level parameter and the respective student-level parameter to determine the contextual effect of institutional retention climate on degree completion. We added the Level-2 variables by block to assess the incremental variance explained and kept non-significant variables to statistically control for their effect on the outcome variable. The final estimates included the delta- $p$ proposed by Peterson (1985) for ease of interpretation. The delta-p reflects the change in probability of persistence that is associated with one unit change in an independent variable (Cabrera 1994; St. John 1991).

\section{Limitations}

This study has several limitations. First, this study is limited by the use of proxy variables for college experience measures. The living on campus measure may not accurately capture a student's actual residence because it only reflects a student's plan at the time of entering college. This study also used high school performance measures, such as high school GPA and SAT composite scores, as a proxy for academic performance in college. Although these high school performance measures have been known to reasonably predict academic performance in college, actual college performance measures, such as college GPA or coursework completed, are desirable.

A second limitation of this study is that we only loosely measured the faculty perceived climate since the faculty database we used for this study came from multiple years. Although we filtered out those faculty members who took the job at their current institution after 1995, the faculty environment measures may not adequately capture the campus climate to which the students in our sample were exposed. However, one would expect relatively stable faculty cultures over a 5 year period. In fact, past research has shown that organizational cultures are not likely to be altered over this short period of time (Bolman and Deal 1997; Lee 2004; Meyer and Scott 1992; Scott 1995). Further, examining HERI's faculty survey publications over this time period yielded little evidence, if any, that faculty behaviors and attitudes were considerably different for the measures we selected (Lindholm et al. 2002). Additionally, it stands to reason that a radical change in faculty perceptions of campus environment as defined by our measures would not be reasonably expected, if one considers the difficulty of hiring faculty of color and recruiting more students of color. The same line of thought could also be extended to include faculty members' adoption of new instructional tools and delivery over a 5 year period.

A final limitation of this study is the sample had considerable missing data (i.e. greater than 10\%) on two Level-1 variables: Degree aspirations (16.6\%) and SAT composite scores $(13.4 \%)$. When we used listwise deletion, it yielded a sample of only 24,621 cases, which is equivalent to a $37 \%$ reduction in the total number of cases. Although there are known issues in using the Expectation-Maximization (EM) algorithm for missing data analysis, such as incorrect standard errors (von Hippel 2004), we proceeded with SPSS EM Missing Values Analysis 14.0 to impute missing values on the Level-1 variables. Our decision relied on at least three reasons. First, the imputation enables us to preserve significantly more cases for 
analysis. Second, the use of EM may be acceptable because the variables that have the most missing values were not of primary interest. Third, despite its limitations, the EM approach is a better choice over traditional methods, such as listwise, pairwise, and dummy variable adjustment when the data are missing at random (Allison 2002).

\section{Results}

\section{Student-Level Variables Related to Degree Completion}

The HGLM analyses show that several student-level variables are significantly associated with the chance of college student persistence to degree completion. Not surprisingly, our results confirm other researchers' findings with respect to background and demographic characteristics. As Table 2 indicates, for a unit increase in a student's high school GPA, a student's probability of persistence to degree completion increases by $5.9 \%$, holding all other variables constant. Similarly, as a student's SAT composite score increases, so does the chance of student persistence. These results have been confirmed in past studies of

Table 2 Estimation of final HGLM model for all measures ( $n=37,006$ at Level-1; $n=170$ at Level-2)

\begin{tabular}{|c|c|c|c|}
\hline Variables & $\begin{array}{l}\text { Coefficients } \\
\text { (log-odds) }\end{array}$ & $\begin{array}{l}\text { Standard } \\
\text { error }\end{array}$ & Delta-p \\
\hline \multicolumn{4}{|l|}{ Student-level fixed effects } \\
\hline Gender: female & .043 & .026 & \\
\hline Race: African American/Black & -.010 & .068 & \\
\hline Race: Latina/o & $-.263 * *$ & .075 & -.061 \\
\hline Race: American Indian & -.438 & .081 & \\
\hline Race: Asian & $.167 *$ & .068 & .036 \\
\hline Race: other race & -.011 & .071 & \\
\hline Socioeconomic status & $.082 * * *$ & .010 & .018 \\
\hline Financial concern & $-.081 * * *$ & .020 & -.018 \\
\hline First generation & -.027 & .040 & \\
\hline Degree aspiration & -.021 & .019 & \\
\hline High school GPA & $.279 * * *$ & .010 & .059 \\
\hline SAT composite score & $.030 * *$ & .010 & .007 \\
\hline Living on campus & $.211 * * *$ & .042 & .045 \\
\hline Intent to stopout & .018 & .025 & \\
\hline Intent to dropout & -.036 & .029 & \\
\hline Intent to transfer & $-.292 * * *$ & .015 & -.067 \\
\hline \multicolumn{4}{|l|}{ Institutional-level fixed effects } \\
\hline \multicolumn{4}{|c|}{ Aggregated institutional characteristics } \\
\hline High school GPA & $.367 * * *$ & .103 & .076 \\
\hline Financial concern & -.183 & .336 & \\
\hline Degree aspiration & -.109 & .264 & \\
\hline Percent: first-generation & -.175 & .744 & \\
\hline Percent: living on campus & .053 & .392 & \\
\hline Percent: female & .219 & .288 & \\
\hline
\end{tabular}


Table 2 continued

\begin{tabular}{|c|c|c|c|}
\hline Variables & $\begin{array}{l}\text { Coefficients } \\
\text { (log-odds) }\end{array}$ & $\begin{array}{l}\text { Standard } \\
\text { error }\end{array}$ & Delta-p \\
\hline \multicolumn{4}{|l|}{ Structural-demographic } \\
\hline Racial diversity & -.006 & .007 & \\
\hline Institutional selectivity & $.228 * * *$ & .061 & .048 \\
\hline Institutional size & .029 & .019 & \\
\hline Private & .258 & .163 & \\
\hline Four-year colleges & .109 & .152 & \\
\hline \multicolumn{4}{|l|}{ Faculty perceived campus climate environment } \\
\hline Institutional priority on teaching and learning & .069 & .147 & \\
\hline Institutional priority on multicultural environment & -.060 & .116 & \\
\hline Active learning & .200 & .165 & \\
\hline \multicolumn{4}{|l|}{ Peer institutional retention climate } \\
\hline Institutional retention: stopout & $1.529 *$ & .606 & .152 \\
\hline Institutional retention: dropout & $-1.970^{*}$ & .808 & -.548 \\
\hline Institutional retention: transfer & $-.973 * *$ & .277 & -.236 \\
\hline \multicolumn{4}{|l|}{ Random effects } \\
\hline \multicolumn{4}{|l|}{ Intercept } \\
\hline Reliability & .847 & & \\
\hline$\chi^{2}$ & $1172.653 * * *$ & & \\
\hline Baseline probability of graduation & & & 0.67 \\
\hline
\end{tabular}

$* p<.05 ; * * p<.01 ; * * * p<.001$

student persistence (Adelman 1999, 2006; Astin and Oseguera 2005). Living on campus rather than off campus increases the probability of persistence by $4.5 \%$ : a finding that has been confirmed in past studies of persistence (Astin 1993; Pascarella and Terenzini 2005; Seidman 2005). The probability of persistence is $6.1 \%$ lower for Latina/o students, and $3.6 \%$ higher for Asian students, compared to White students. Again, a finding that has been confirmed in previous work (Astin and Oseguera 2005; Oseguera 2005-2006). A student's socioeconomic status is positively associated with the chance of persistence, while a unit increase in a student's financial concern decreases the probability of persistence by $1.8 \%$. Students who perceive higher chances of transferring to other institutions at the time of entering college are also less likely to persist, suggesting that the student already exhibited a predisposition that would make non-persistence at the institution of initial entry not surprising. Although it does elicit another puzzle, specifically, why would a student entering a four-year institution already expect to transfer to another institution before any experience with the initial institution of entry. According to Newman and Couturier (2001), when education institutions treat students as consumers, students respond by attending multiple institutions to meet their specific needs.

\section{Influence of Peer Environment on Degree Completion}

The final HGLM results show that the average chance of persistence is related to peer institutional retention climate (which is captured by aggregated measures of students' intentions to dropout, stopout, or transfer), and institutional selectivity but unrelated to faculty-perceived campus climate environments. Specifically, the probability of persistence 
decreases by $23.6 \%$ for one standard deviation increase in the aggregated measure of intention to transfer to another college. The probability of persistence also decreases by $54.8 \%$ for one standard deviation increase in the aggregated measure of intention to dropout, whereas the probability of persistence increases $15.2 \%$ for one standard deviation increase in the aggregated measure of intention to leave college temporarily. One explanation for this may be that stopouts intend to return to the campus and eventually will complete their studies. Researchers have documented that $25-30 \%$ of undergraduates take some time off from college but subsequently return (Berkner 2002; Carroll 1989). These interpretations refute Avalos' (1996) finding that stopouts resembled non-completers more than the completers, although this may be due to his ability to evaluate persistence over a longer time period. Nevertheless, this finding confirms Bank et al.'s (1990) research that highlighted behavioral differences between students with transfer intentions, lay out intentions (i.e. stopout) and those with dropout intentions. Clearly, more attention to students' varying precollege intentions and their subsequent influence on retention is warranted.

Although the aggregated measures of student characteristics, which represent the institutional composition of students, are not of primary interest, it is worth noting that some of these measures surfaced as significant. Higher probability of persistence is associated with higher percentages of peers with strong high school GPA's (7.6\%), as well as enrolling in a more selective college $(4.8 \%)$. The quality of the undergraduate student body has been shown to produce educational benefits to the students attending these types of quality institutions (Carnevale and Rose 2003). Combined with the effect of institutional retention climate, this suggests that peer environments in four-year colleges and universities play a significant role in persistence to degree completion. This work extends the work of Bowen and Bok (1998) who show the positive effect of attending highly selective institutions on students' persistence decisions to also include institutions of lesser selectivity. In other words, peer contexts do play an important role in persistence above individual attributes and peer-peer interactions.

\section{Multivariate Hypothesis Tests}

To determine the contextual effect of the aggregated peer institutional retention climate measures on persistence to degree completion, multivariate hypothesis tests of the difference between student-level parameter estimates of the three withdrawal intention measures and the respective aggregated institutional-level parameter estimates were conducted. Multivariate hypothesis testing allows one to further establish if in fact there is an environmental impact on the outcome measure. Table 3 indicates that there were statistically significant differences between institutional climate of transferring, dropping out, or stopping out and the corresponding student-level intention measures. The finding suggests that the institutional retention climate has a contextual effect on persistence to degree completion. In other words, even after controlling for a student's personal likelihood of withdrawing either temporarily or permanently, enrolling in an institution where that sentiment is expressed by others in the student body has an independent effect on a student's eventual degree completion behavior.

\section{Influence of Faculty Perceived Climate for Undergraduates}

The results produce little evidence that faculty perceived campus climates as defined by emphasis on the teaching/learning function, emphasis on multicultural environments, and use of active learning contribute to student persistence behavior. 
Table 3 Multivariate hypothesis tests of difference between student-level retention measures and the respective institution-level climate measures

\begin{tabular}{lcccc}
\hline Measures (Level-2/Level-1) & \multicolumn{3}{l}{ Coefficient (log-odds) } & \\
\cline { 2 - 5 } & Institutional-level & Student-level & Difference & $\chi^{2}$ \\
\hline Stopout climate/intention & 1.523 & .018 & 1.505 & $6.868^{*}$ \\
Dropout climate/intention & -1.970 & -.036 & -1.934 & $7.570^{*}$ \\
Transfer climate/intention & -.973 & -.292 & -.681 & $392.111^{* * *}$ \\
\hline
\end{tabular}

$* p<.05 ; * * p<.01 ; * * * p<.001$

\section{Variance Explained by HGLM Models}

Table 4 shows the estimated variance components for all the models. The final institutionlevel model explained $69.1 \%$ of the variance in mean persistence rates among four-year colleges and universities. The majority of variance (58.2\%), however, was explained by differences in the individual characteristics and student composition. The addition of structural, demographic, and faculty perceived campus climate environment measures increased the explained variance by about $7 \%$ while peer institutional retention climate measures further increased the explained variance from $65.3 \%$ to $69.1 \%$. This is an important contribution to our understanding of retention rates. That is, the persistence ethos at the college appears to influence individual level persistence.

\section{Discussion}

The main contribution of this work lies in the ability to show that institutional retention climates do influence retention probabilities. The combined theoretical frame guiding the study is particularly useful because particular emphasis is placed on the unique effects of peer normative contexts or institutional climate on student persistence. We found that measures of intentions to leave had contextual effects on student persistence. The difference in the logodds between institutional-level intention to leave and student-level intention to leave was statistically significant. Attending a college where students' collectively report a certain behavior such as likelihood of transferring, dropping out, or stopping out has independent

Table 4 Variance explained by HGLM models

\begin{tabular}{lll}
\hline HGLM model & Parameter & Variance explained \\
\hline Mean persistence rates $\left(\beta_{0}\right)$ & \\
Intercept $\left(\gamma_{00}\right)$ & .742 & \\
Variance $\left(\tau_{00}\right)$ & $.588^{* * *}$ & \\
$\quad$ Level 1 with aggregated institutional characteristics & $.246^{* * *}$ & $58.2 \%$ \\
$\quad+$ Structural-demographic & $.205^{* * *}$ & $65.1 \%$ \\
$\quad+$ Faculty perceived campus climate environment & $.204^{* * *}$ & $65.3 \%$ \\
$\quad+$ Institutional retention climate & $.182 * * *$ & $69.1 \%$ \\
\hline
\end{tabular}

Note: Since the outcome variable in this study is dichotomous, we presented the variance explained at the institutional level and used the equation: $\left[\tau_{00}\right.$ (unconditional) $-\tau_{00}$ (conditional) $] / \tau_{00}$ (unconditional) (see Rumberger 1995; Raudenbush and Bryk 2002)

$* p<.05 ; * * p<.01 ; * * * p<.001$ 
effects above students' own likelihood of engaging in these behaviors. Interestingly, these three peer climate intentions operate in different ways. In examining the simple correlations between the Level-2 institutional variables, attending an institution with higher proportions of students saying they are going to stopout, ultimately has a positive relationship with persistence because those saying they are going to stop out also attend schools with higher SES peers (.146), they are in schools with peers with higher standardized test scores (.208) and schools with higher proportions of students living in dorms (.233). These conditions reflect the benefits of attending well-resourced schools. Exposure to a peer environment with wealthier and academically strong peers can encourage students to remain enrolled in school and complete college even if their original expectation was to stopout.

Conversely, if one examines the relationships between transfer intentions, it makes sense why this peer climate would be related to not completing in 6 years; this variable is negatively related to aggregated first-generation status (-.250), lower student body GPA (-.452), and lower student body SES (-.445), and these students are less likely to attend schools with higher percentages of students residing in dorms (-.242). Attending schools with higher proportions of students expressing financial concern (.376) is also positively related to transfer climate. This potentially indicates lower SES students' lack of familiarity with different college systems. Kirst and Venezia (2004) noted traditionally underrepresented students' misconceptions about their knowledge of different institution types. Further, Kirk-Kuwaye and Kirk-Kuwayne (2007) documented the difficulties students encounter when they engage in lateral transfer i.e. from one-four-year to another four-year institution more so than vertical transfer i.e. from one-two-year to a four-year institution. In this study, transfer climates are found in institutions that enroll lower SES students and lower prepared students. This is an important finding for schools that enroll traditionally underrepresented and/or under-prepared students as these students do not necessarily report they plan to dropout or even stopout, but they do report they plan to transfer. This implies a real mismatch between students' expectations and their realities.

Finally, the dropout climate's relationship to individual degree completion differs from the transfer climate's or stopout climate's relationship. That is, dropout climate is related to lower peer degree aspirations (-.176) and lower peer GPA's (-.177) similar to transfer climate but unrelated to peer SES, peer first generation status, or peer standardized test scores as we see with stopout climates. In short, these interpretations reflect the influence of institutional retention climates above and beyond individual influences.

This work provides evidence that peer climates have the potential to impact educational outcomes independent of one's own attitudes and expectations. These findings reinforce past assertions that the contextual effect of peers i.e. expectations and standards, are even stronger influences on student behavior than is the modeling behavior or the pressure to copy behavior (Bank et al. 1990; Steele 1997). In other words, attending a campus where there is an intensive transfer culture might encourage students who may not otherwise transfer to actually transfer. Perhaps campuses have overlooked this attitude and focused on students whose intention it was to dropout or stopout. Similarly, attending a campus where there is an intensive stopout culture could be mollified if a student is in an academically and financially strong peer environment. Colleges and universities should pay close attention to what the institutional ethos is of the college. Perhaps this is not an easy feat to accomplish, but one that merits attention nonetheless. Clearer understanding of how peers' attitudes shape a student's persistence behavior is an area needed to better shape institutional practices and policies to improve retention rates.

The second major contribution of this study is the inclusion of faculty perceived climates for undergraduates as potential influences of persistence. In this study though, it may be that 
measures of faculty reported behaviors and perceptions do not accurately measure the sentiments students' actually hold or students' actual behavior. Perhaps student measures of how frequently they engage in active learning activities or how much they perceive that the faculty is interested in student learning may shed more light on the retention puzzle than mere descriptions of the frequency with which faculty deliver these types of pedagogies. Nevertheless, this is an area for further study as a small amount of variance was explained by the faculty perceived climate utilized in this study. Future research might examine whether the faculty perceived climates operate differently depending on the time frame under which degree completion is measured. That is, might we expect differences in teaching/learning if we evaluated degree completion within 4, 5, or 6 plus years? Another area for research is examining how or whether faculty perceptions of climate operate differently for students attending commuter versus residential campuses. We expect that faculty contact hours may differ and thus result in different effects on student persistence behavior but did not test this assertion because there were too few commuter campuses in this sample to examine.

In addition to variables that entered as significant, non-significant findings also merit discussion. One major non-significant finding is the racial diversity on campus. Higher proportions of underrepresented students of color do not enhance an individual's chances of staying in college but neither does it hinder degree completion. This means there are some colleges with high diversity that are doing well and some are doing poorly. Thus it is not that a college is diverse that contributes to low retention, it is that students may enter disadvantaged or with lower preparation (e.g., inequality is the problem). This speculation is supported by the fact that peer high school GPA also helped explain differences in completion chances. Not only does individual high school grade average increase the probability of completing a degree so does enrolling in a college where one's peers also earned higher marks in high school.

As our conceptual model posited, several student and institution level variables helped to explain persistence. Specifically, this study supported the claim that persistence is positively influenced by the academic preparation of both the individual student and his/her peers. The fact that probabilities in completing college were influenced by students' socioeconomic status and individual financial concern may be one reason they do not stay until graduation.

\section{Conclusion and Implications for Research and Practice}

While past research has overlooked peer and faculty perceived campus climates, the results from this work call for the attention of peer institutional retention climates. Having controlled for a variety of individual attitudes and characteristics, we found that peer climates as defined by a student body's aggregated report of stopout, dropout, or transfer intentions, did independently determine whether a student would persist or not as did a campus' overall retention rate. Perhaps as Clark (1960) characterized community colleges some 45 years ago regarding their capacity to mollify student aspirations and to reduce the students' ability to complete their intended academic studies, certain four-year institutions today are also serving to "cool" students out (Clark 1960, 1980). This is especially evident in schools where larger proportions of students maintain transfer intentions. Conversely, schools with academically prepared students and better resourced students can serve as a buffer against stopping out for students whose initial intentions it was to stopout of college. This study raises more questions for future study such as how would different peer contexts such as choice of major influence individual behavior and what is it about the overall campus retention rates and aggregated attitudes of students that contribute independently to 
student persistence? Have campuses transformed peer norms in recent years? Are certain four-year colleges operating more as "revolving" door colleges? Would the findings differ if we were to examine degree completion within different time frames?

Results of this work may encourage campus personnel to attend more closely to student attitudes and highlight yet one more reason for campus administrators to pay attention to institutional climates. One major practical implication of this work includes attention to the transfer intentions of students at college entry. Above students' intentions to dropout or stopout were students' intentions to transfer to another institution. Campuses can be more introspective and determine why entering freshmen hold transfer aspirations especially since this finding is counterintuitive since this study did not include 2-year institutions and it included primarily residential colleges. One would expect transfer intentions at 2-year colleges but not at residential four-year colleges. This implies a real mismatch between first-generation and low income students' expectations and their realities for completing college. With respect to stopout climates, this work highlights the significance of enrolling in better resourced schools. Campuses that enroll students with stopout intentions can in fact retain them if there is a strong peer climate. The fact that institutions can identify whether large numbers of their students intend to stay or leave at the outset using these data is tremendous.

Open Access This article is distributed under the terms of the Creative Commons Attribution Noncommercial License which permits any noncommercial use, distribution, and reproduction in any medium, provided the original author(s) and source are credited.

\section{Appendix}

See Tables 5, 6

Table 5 Multicollinearity diagnostics results for institutional measures

\begin{tabular}{ll}
\hline Variable & VIF \\
\hline Institutional selectivity & 5.17 \\
Degree aspiration & 4.66 \\
Institutional retention: stopout & 4.24 \\
High school GPA & 3.87 \\
Institutional size & 3.86 \\
Percent: first-generation & 3.60 \\
Institutional retention: dropout & 3.48 \\
Private & 2.95 \\
Institutional retention: transfer & 2.63 \\
Four-year colleges & 2.55 \\
Financial concern & 2.48 \\
Institutional priority on teaching and learning & 2.42 \\
Percent: Living on campus & 1.79 \\
Institutional priority on multicultural environment & 1.77 \\
Percent: female & 1.67 \\
Institutional priority: active learning & 1.65 \\
Racial diversity & 1.32 \\
Mean VIF & 2.95 \\
\hline
\end{tabular}


Table 6 Faculty perceived campus environment measures from HERI faculty data $(1995,1998,2001)$

\begin{tabular}{ll}
\hline Measure & $\begin{array}{l}\text { Factor } \\
\text { loadings ('95) }\end{array}$ \\
\hline
\end{tabular}

Institutional priority on teaching and learning (4 items)

$.76 / .73 / .76$

To help students examine and understand their personal values ${ }^{\mathrm{a}} \quad .81$

To develop leadership ability among students ${ }^{\mathrm{a}} \quad .78$

$\begin{array}{ll}\text { To help students learn how to bring about change in American society } & \text { a } \\ .78\end{array}$

To promote the intellectual development of students ${ }^{\mathrm{a}} .69$

Institutional priority on multicultural environment ( 2 items)

$.80 / .80 / .84$

To recruit more minority students ${ }^{\mathrm{a}}$

.91

To create a diverse multi-cultural campus environment ${ }^{\mathrm{a}}$

.91

Active learning (4 items)

$.72 / .72 / .71$

Cooperative learning (small groups) ${ }^{\mathrm{b}} \quad .85$

$\begin{array}{ll}\text { Group projects }^{\mathrm{b}} & .89\end{array}$

$\begin{array}{ll}\text { Experiential learning/field study }^{\mathrm{b}} & .67\end{array}$

Class discussions ${ }^{\mathrm{b}} \quad .64$

\footnotetext{
a $1=$ low priority to $4=$ highest priority

b $1=$ none to $4=$ all
}

\section{References}

Adelman, C. (1999). Answers in the toolbox: Academic intensity, attendance patterns, and bachelor's degree attainment. Washington, DC: U.S. Department of Education: Office of Educational Research and Improvement.

Adelman, C. (2006). The toolbox revisited: Paths to degree completion from high school through college. Washington, DC: U.S. Department of Education.

Allison, P. (2002). Missing data. Thousand Oaks, CA: Sage Publications, Inc.

Astin, A. W. (1964). Personal and environmental factors associated with college dropouts among high aptitude students. Journal of Educational Psychology, 55, 276-287.

Astin, A. W. (1993). What matters in college: Four critical years revisited. San Francisco: Jossey-Bass.

Astin, A. W., Korn, W. S., Sax, L. J., \& Mahoney, K. M. (1994). The American freshman: National norms for fall 1994. Los Angeles: Higher Education Research Institute, UCLA.

Astin, A. W., \& Oseguera, L. (2005). Degree attainment rates at American college and universities. Revised edition. Los Angeles: Higher Education Research Institute, UCLA.

Avalos, J. (1996). The effects of time to degree completion, stopping out, transferring, and reasons for leaving college on students' long term retention, educational aspirations, occupational prestige, and income. Unpublished doctoral dissertation. University of California, Los Angeles.

Bank, B., Slavings, R., \& Biddle, R. (1990). Effects of peer, faculty, and parental influences on students' persistence. Sociology of Education, 63, 209-225.

Bean, J. P. (1980). Dropouts and turnover: The synthesis and test of a causal model of student attrition. Research in Higher Education, 12, 155-187.

Bean, J. P. (1990). Why students leave: Insights from research. In D. Hossler \& J. P. Bean (Eds.), The strategic management of college enrollments. San Francisco: Jossey-Bass.

Berger, J. B. (2000). Organizational behavior at colleges and student outcomes: A new perspective on college impact. Review of Higher Education, 23(2), 177-198.

Berger, J. B. (2001-2002). Understanding the organizational nature of student persistence: Empiricallybased recommendations for practice. Journal of College Student Retention, 3(1), 3-21.

Berger, J. B., \& Braxton, J. M. (1998). Revising Tinto's internationalist theory of student departure through theory elaboration: Examining the role of organizational attributes in the persistence process. Research in Higher Education, 39(2), 103-120. 
Berger, J. B. \& Milem, J. F. (2000). Organizational behavior in higher education and student outcomes. In J. Smart (Ed.), Higher education: Handbook of theory and research (Vol. 15, pp. 268-338). New York: Agathon Press.

Berkner, L. (2002). Descriptive summary of 1995-1996 beginning postsecondary students: Six years later. Washington, DC: National Center for Education Statistics.

Bolman, L. G., \& Deal, T. E. (1997). Reframing organizations: Artistry, choice, and leadership. San Francisco: Jossey Bass.

Bonous-Hammarth, M. (2000). Value congruence and organizational climates for undergraduate persistence. In J.C. Smart (Ed.) Higher education: Handbook of theory and research (Vol. 15, pp. 339-370). New York: Agathon Press.

Bowen, W. G., \& Bok, D. C. (1998). The shape of the river. Princeton, NJ: Princeton University Press.

Braxton, J. (2000). Reworking the student departure puzzle. Nashville, TN: Vanderbilt Press.

Braxton, J., Eimers, M. T., \& Bayer, A. (1996). The implications of teaching norms for the improvement of undergraduate education. Journal of Higher Education, 67(6), 603-625.

Braxton, J., \& Hirschy, A. (2005). Theoretical development in the study of college student departure. In A. Seidman (Ed.), College student retention: Formula for success (pp. 61-87). Westport, CT: Greenwood Publishing Group.

Braxton, J., Hirschy, A., \& McClendon, (2004). Understanding and reducing college student departure. No. 3. ASHE-ERIC Higher Education Research Report Series. San Francisco: Jossey-Bass.

Braxton, J., Milem, J., \& Sullivan, A. S. (2000). The influence of active learning on the college student departure process: Toward a revision of Tinto's Theory. Journal of Higher Education, 71(5), 569-590.

Cabrera, A. F. (1994). Logistic regression analysis in higher education: An applied perspective. In J. C. Smart (Ed.), Higher education: Handbook of theory and research X (pp. 225-256). New York: Agathon Press.

Cabrera, A. F., Burkum, K. R., \& La Nasa, S. M. (2005). Pathways to a four-year degree: Determinants of transfer and degree completion. In A. Seidman (Ed.), College student retention: Formula for success (pp. 155-214). Westport, CT: Greenwood Publishing Group.

Cabrera, A. F., \& Nora, A. (1996). The role of perception and prejudice on the adjustment of minority students to college. Journal of Higher Education, 67(2), 119-148.

Cabrera, A. F., Nora, A., \& Castaneda, M. B. (1993). College persistence: Structural equations modeling test of an integrated model of student retention. Journal of Higher Education, 64(2).

Carnevale, A. P., \& Rose, S. J. (2003). Socioeconomic status, racelethnicity, and selective college admissions. New York: Report for the Century Foundation.

Carroll, C. D. (1989). College persistence and degree attainment for 1980 high school graduates: Hazards, for transfers, stopouts, and part-timers. Washington, DC: National Center for Education Statistics.

Chang, M. J. (1999). Does racial diversity matter? The educational impact of a racially diverse undergraduate education. Journal of College Student Development, 40(4), 377-395.

Clark, B. R. (1960). The "Cooling-Out" function in higher education. The American Journal of Sociology, 65(6), 569-576.

Clark, B. R. (1980). The "Cooling-Out" function revisited. New Directions for Community Colleges, 8(4), 15-31.

Cohen, J., Cohen, P., West, S. G., \& Aiken, L. S. (2003). Applied multiple regression/correlation analysis for the behavioral sciences (3rd ed.). London: Lawrence Erlbaum Associates, Publishers.

Comeaux, E. (2005a). Unveiling stereotypes of nontraditional student groups on college campuses: An organizational and Critical Race Theory analysis of faculty attitudes toward male and female studentathletes. Unpublished doctoral dissertation. University of California, Los Angeles.

Comeaux, E. (2005b). Environmental predictors of academic achievement among student-athletes in the revenue-producing sports of men's basketball and football. The Sport Journal, 8(3).

Conchas, G. Q. (2006). The color of success. Race and high achieving urban youth. New York: Teachers College Press.

Dey, E. L. (1996). Undergraduate political attitudes: An examination of peer, faculty, and social influences. Research in Higher Education, 37(5), 535-554.

Feldman, K. A., \& Newcomb, T. M. (1969). The impact of college on students. San Francisco: Jossey-Bass.

Hausmann, L. R. M., Schofield, J. W., \& Woods, R. L. (2007). Sense of belonging as a predictor of intentions to persist among African American and White first-year college students. Research in Higher Education, 48(7), 803-839.

Holland, J. (1997). Making vocational choices. A theory of vocational personalities and work environments. Englewood Cliffs, NJ: Prentice Hall.

Hurtado, S., \& Carter, D. F. (1997). Effects of college transition and perceptions of the campus racial climate on Latino college students' sense of belonging. Sociology of Education, 70, 324-345. 
Hurtado, S., Milem, J. F., Clayton-Pedersen, A., \& Allen, W. R. (1999). Enacting diverse learning environments. Improving the climate for racial/ethnic diversity in higher education. Washington, DC: George Washington University Press.

Hurtado, S., \& Ponjuan, L. (2005). Latino educational outcomes and the campus climate. Journal of Hispanic Higher Education, 4(3), 235-251.

Kirk-Kuwaye, C., \& Kirk-Kuwayne, M. (2007). A study of engagement patterns of lateral and vertical transfer students during their first semester at a public research university. Journal of the First-Year Experience \& Students in Transition, 19(2), 9-27.

Kirst, M. W., \& Venezia, A. (2004). From high school to college: Improving opportunities for success in postsecondary education. San Francisco: Jossey Bass.

Kuh, G. D. (2001-2002). Organizational culture and student persistence: Prospects and puzzles. Journal of College Student Retention, 3(1): 23-39.

Lee, J. J. (2004). Comparing institutional relationships with academic departments: A study of five academic fields. Research in Higher Education, 45(6), 603-624.

Lindholm, J., Astin, A. W., Sax, L., \& Korn, W. (2002). The American college teacher: National norms for the 2001-2002 HERI Faculty Survey. Los Angeles: Higher Education Research Institute, UCLA.

Locks, A., Hurtado, S., Bowman, N., \& Oseguera, L. (2008). Extending notions of campus climate and diversity to the transition to college. Review of Higher Education, 31(3), 257-285.

McEwan, P. J., \& Soderberg, K. (2006). Roommate effects on grades: Evidence from first-year housing arrangements. Research in Higher Education, 47(3), 347-370.

Meyer, J. W., \& Scott, W. R. (1992). Organizational environments: Ritual and rationality. Thousand Oaks, CA: Sage Publications.

Milem, J. F. (1998). Attitude change in college students: Examining the effect of college peer groups and faculty normative groups. Journal of Higher Education, 69(2), 117-140.

Newman, F., \& Couturier, L. K. (2001, September-October). The new competitive arena: market forces invade the academy. Change, 33(5), 10-17.

Oseguera, L. (2005-2006). Four and six-year baccalaureate degree completion by institutional characteristics and racial/ethnic groups. The Journal of College Student Retention, 7(1-2), 19-59.

Pascarella, E. T., \& Terenzini, P. (1991). How college affects students. San Francisco: Jossey-Bass Publishers.

Pascarella, E. T., \& Terenzini, P. (2005). How college affects students: A third decade of research (Vol. 2). San Francisco: Jossey-Bass Publishers.

Peterson, T. (1985). A comment on presenting results from logit and probit models. American Sociological Review, 50(1), 130-131.

Pike, G. R., \& Kuh, G. (2006). Relationships among structural diversity, informal peer interactions, and perceptions of campus environment. Review of Higher Education, 29(4), 425-450.

Porter, S. R., \& Swing, R. L. (2006). Understanding how first-year seminars affect persistence. Research in Higher Education, 47(1), 89-109.

Raudenbush, S. W., \& Bryk, A. S. (2002). Hierarchical linear models: Applications and data analysis methods. Thousand Oaks, CA: Sage Publications, Inc.

Rumberger, R. W. (1995). Dropping out of middle school: A multilevel analysis of students and schools. American Educational Research Journal, 32(3), 583-625.

Rumberger, R. W., \& Thomas, S. L. (2000). The distribution of dropout and turnover rates among urban and suburban high schools. Sociology of Education, 73(1), 39-67.

Sacerdote, B. (2001). Peer effects with random assignment: Results from Dartmouth roommates. Quarterly Journal of Economics, 116(2), 681-704.

Scott, W. R. (1995). Institutions and organizations. Thousand Oaks, CA: Sage Publications.

Seidman, A. (2005). College student retention: Formula for Success. Westport, CT: Praeger Publishers.

Sjoberg, C. E. (1999). The relationship of environmental predictors and institutional characteristics to student persistence. Unpublished doctoral dissertation, Oklahoma State University.

St. John, E. P. (1991). What really influences minority attendance? Sequential analyses of the high school and beyond sophomore cohort. Research in Higher Education, 32(2), 141-158.

Steele, C. (1997). A threat in the air: How stereotypes shape intellectual identity and performance. American Psychologist, 52(6), 613-629.

Thomas, S. (2000). Ties that bind: A social network approach to understanding student integration and persistence. Journal of Higher Education, 71(5), 591-615.

Tierney, W. G. (1990). Assessing academic climates and culture, new directions for institutional research, No. 68. San Francisco: Jossey-Bass.

Tierney, W., \& Colyar, J. (2005). The role of peer groups in college preparation programs. In W. Tierney, Z. Corwin, \& J. Colyar (Eds.), Preparing for college: Nine elements of effective outreach (pp. 49-68). Albany: State University of New York Press. 
Tinto, V. (1975). Dropouts from higher education: A theoretical synthesis of recent research. Review of Educational Research, 45, 89-125.

Tinto, V. (1993). Leaving college: Rethinking the causes and cures of student attrition (2nd ed.). Chicago: University of Chicago Press.

Titus, M. A. (2004). An examination of the influence of institutional context on student persistence at 4-year colleges and universities: A multilevel approach. Research in Higher Education, 45(7), 673-699.

Titus, M. A. (2006a). Understanding the influence of the financial context of institutions on student persistence at four-year colleges and universities. Journal of Higher Education, 77(2), 353-375.

Titus, M. A. (2006b). Understanding college degree completion of students with low socioeconomic status: The influence of the institutional financial context. Research in Higher Education, 47(4), 371-398.

von Hippel, P. T. (2004). Biases in SPSS 12.0 missing value analysis. The American Statistician, 58(2), 160164.

Weidman, J. C. (1989). Undergraduate socialization: a conceptual approach. In J. Smart (Ed.), Higher education: Handbook of theory and research (Vol. V). NY: Agathon Press.

Winston, G. C., \& Zimmerman, D. J. (2004). Peer effects in higher education. In C. M. Hoxby (Ed.), College choices: The economics of where to go, when to go, and how to pay for it (pp. 395-421). Chicago: University of Chicago Press.

Zimmerman, D. J. (2003). Peer effects in academic outcomes: Evidence from a natural experiment. Review of Economics and Statistics, 85(1), 9-23. 